\title{
Formation and Development of Ecofriend Antimicrobial Superabsorbent Hydrogel for Personal Healthcare
}

\author{
Md. Ibrahim H. Mondal ${ }^{1 *}$, Md. Obaidul Haque${ }^{1}$, Md. Nahid Pervez ${ }^{2}$, Md Roknuzzaman¹, Md. \\ Nazmul Huda ${ }^{1}$ and Moslima Khatun ${ }^{1}$ \\ ${ }^{1}$ Polymer and Textile Research Lab, Department of Applied Chemistry \& Chemical Engineering, Rajshahi University, Rajshahi \\ 6205, Bangladesh
}

${ }^{2}$ Hubei Provincial Engineering Laboratory for Clean Production and High Value Utilization of Bio-based Textile Materials, Wuhan Textile University, Wuhan, 430200, China

*Corresponding author: Md. Ibrahim H. Mondal, Polymer and Textile Research Lab, Department of Applied Chemistry \& Chemical Engineering, Rajshahi University, Rajshahi 6205, Bangladesh

\section{ARTICLE INFO}

Received: 幽 September 14, 2020

Published: 陆 September 28, 2020

Citation: Md. Ibrahim H. Mondal, Md. Obaidul Haque, Md. Nahid Pervez, Md. Roknuzzaman, Md. Nazmul Huda, Moslima Khatun. Formation and Development of Ecofriend Antimicrobial Superabsorbent Hydrogel for Personal Healthcare. Biomed J Sci \& Tech Res 30(5)-2020. BJSTR. MS.ID.005000.

Keywords: Carboxymethyl cellulose; Biodegradable; Hydrogel; Water absorption; Biodegradable; anti-microbial activity; Personal healthcare product

\begin{abstract}
Cellulose-based biodegradable hydrogel was synthesized with a good absorption and antimicrobial activity for a target applications in personal health care sector. Hydrogel was synthesized by simple and energy efficient free radical graft copolymerization between acrylamide and methyl methacrylate with $\mathrm{CMC}$, in presence of crosslinking agent $\mathrm{N}, \mathrm{N}$ methylne-bis-acrylamide and potassium persulphate as initiator. For synthesis of two different antimicrobial hydrogels, two antimicrobial agents $\mathrm{ZnO}$ and $\mathrm{TiO}_{2}$ were added during polymerization reaction. The obtained products were characterized by physical methods as well as instrumental techniques. It was found that hydrogels with $\mathrm{ZnO}$ and $\mathrm{TiO}_{2}$ separately are active against gram positive and gram negative microorganism and have the water absorption capacity of 190 and $173 \mathrm{~g} / \mathrm{g}$ respectively. In addition water holding capacity of the hydrogels decreases with the increase of antimicrobial agent, at the same time with increase of their antimicrobial activity. From the experimental analysis it can be concluded that the synthesized hydrogel could be a good initiative in the handle of complicacy originates from personal healthcare products as well as created opportunities for the products to be used in replacement of available petrochemical based super absorbent polymer.
\end{abstract}

\section{Introduction}

Hydrogels are hydrophilic natural or synthetic polymeric substance with water absorbing capability which swell in water and retain a significant amount of water within the structure without dissolving [1-3]. Either chemical or physical crosslinking takes place during hydrogel synthesis. They attract polar solvents like water due to inherent of polar functional groups such as $-\mathrm{OH}$, $-\mathrm{COOH},-\mathrm{CONH}_{2},-\mathrm{CONH},-\mathrm{SO}_{3} \mathrm{H}$, etc. in their backbone [4]. Due to restless research of scientists various expected and attractive properties, such as, sensitive to $\mathrm{pH}$, biodegradable, easy to synthesis and give shape, have high swelling tendency etc., have been inherited by hydrogels, so it can be used in biomedical application [5], personal healthcare [6,7], construction [8], agriculture [9] and other industrial applications including soft contact lenses, lubricating surface coatings, phantoms for ultrasound- based imaging, controlled drug release devices, wound healing dressings, cell immobilization islets, three-dimensional cell culture substrates, and bioactive scaffolds for regenerative medicine [10-15].

At present most of the super absorbents using in different purposes including personal health care are petrochemical based and non-biodegradable. The two main personal care products are baby diaper and famine napkin where super absorbent polymers are used. As most of the used hydrogels don't contain antimicrobial agents, they are unable to prevent attack from microorganism. So, skin rash to children and other complicacy are faced by the consumer of the personal care products. It has been observed by scientists that cellulose based hydrogels show better water absorption capability 
and biodegradability, in this respect scientists have found success by incorporating natural polymer such as cellulose, starch, chitosan, proteins, carrageenan etc. in polymeric chain [16]. Cellulose is most abundant, ubiquitous and biodegradable natural polymer which is used in various purposes from ancient time to till today [17]. Many researchers have been found success in biomaterials synthesis especially bio-adsorbent from lignocellulosic substances such as wood saw dust, crop milling waste, sugarcane bagasse, bamboo plant waste and other lingo cellulosic sources [18-20]. Chemical modification is the most common technique to alter the properties of the naturally- occurring biopolymers such as polysaccharides. The agents $\left(\mathrm{ZnO}\right.$ and $\left.\mathrm{TiO}_{2}\right)$ are relatively cheap and show good skin protective activity in various products. Super absorbent (hydrogel) can be prepared by various methods but among them free radical graft copolymerization technique is the most widely used due to its simple reaction technique and less expensive instruments. Cellulose-based hydrogels can be synthesized through any one of the following paths,

a) graft copolymerization of hydrophilic vinyl monomers onto cellulose and its derivatives, with and simultaneous crosslinking of the chain and

b) crosslinking by difunctional monomers onto cellulose and its derivatives.

In this research work antimicrobial biodegradable hydrogel was synthesized by graftcopolymerization reaction of $\mathrm{CMC}$ with acrylamide (Am) and methyl methacrylate (MMA) using $\mathrm{N}, \mathrm{N}$ methylene-bis-acrylamide (MBA) as a crosslinker in presence of initiator potassium persulphate $\left(\mathrm{K}_{2} \mathrm{~S}_{2} \mathrm{O}_{8}\right)$. In addition two antimicrobial agents $\left(\mathrm{ZnO}\right.$ and $\left.\mathrm{TiO}_{2}\right)$ were added during preparation reaction to form two different samples [21]. To bring necessary and expected properties to synthesized products the effects of various parameters such as temperature, monomer concentration, initiator and crosslinker concentration on synthesis, as well as on fundamental properties like free water absorption capacity and swelling behaviors of the hydrogel, under different conditions, were investigated. The products were also characterized by physical techniques as well as instrumental techniques like Fourier transform infrared spectroscopy (FTIR), scanning electron microscopy (SEM) and thermogravimetric analysis (TG). Finally it can be concluded as- the antimicrobial hydrogel would be a good initiative for fighting against complicacy arises from personal care products $[22,23]$.

\section{Experimental}

\section{Materials}

Required chemicals like carboxymethylcellulose (CMC) as cellulosic source, monomers, antimicrobial agents and other essential chemicals were purchased from BDH, Sigma-Aldrich etc.

\section{Preparation Of CMC-G-Poly (Acrylamide-Co-MMA)-Zno/ $\mathrm{TiO}_{2}$ Anti-Microbial Hydrogel}

For the synthesis of CMC-g-poly (acrylamide-co-MMA)-ZnO/ $\mathrm{TiO}_{2}$ anti-microbial hydrogel, 0.5g of CMC was immersed in $15 \mathrm{ml}$ of distilled water at $70^{\circ} \mathrm{C}$ in three necked flask fitted with magnetic stirrer, a reflux condenser and a nitrogen line for bubbling $30 \mathrm{~min}$ before starting reaction. Initially $0.05 \mathrm{~g}$ of initiator $(10 \% \mathrm{w} / \mathrm{w}$ based on dry CMC weight) was dissolved and added to the CMC solution for $10 \mathrm{~min}$. The total volume of the solution was controlled to $40 \mathrm{ml}$. Thereafter $1.5 \mathrm{~g}$ of $\mathrm{AM}(300 \% \mathrm{w} / \mathrm{w}$ based on dry cotton weight) and $1.5 \mathrm{~g}$ of MMA $(300 \% \mathrm{w} / \mathrm{w}$ based on dry CMC weight) were added and the mixture was stirred for $30 \mathrm{~min}$. Antimicrobial agents ( $\mathrm{ZnO}$ and $\mathrm{TiO}_{2}$ ) were also added in this period in separately to prepare different agent containing hydrogel. Then the reaction was proceeded without stirring for $2 \mathrm{~h}$ more. The prepared hydrogels were washed with distilled water for several days, consequently with ethanol for dewatering and immersed in $\mathrm{NaOH}$ solution for 24 h. Finally the hydrogel was washed with distilled water and dried in oven at $60^{\circ} \mathrm{C}$ for $24 \mathrm{~h}[24]$.

\section{Water Absorption Capacity of Hydrogels}

When absorption of surroundings fluid is the main target, water absorption capacity is the fundamental property of hydrogels. For the determination of the property pre-weighed sample was immersed in distilled water (for $24 \mathrm{~h}$ ) and weighed again to remove surface water by gently dabbing with tissue paper. The water absorbency was calculated by the equation [25]:

$$
\mathrm{Qeq}=(\mathrm{Weq}-\mathrm{Wo}) / \mathrm{Wo}(1)
$$

Where Wo is weight of dry hydrogel, Weq is the weight of wet hydrogel at equilibrium and Qeq is the water absorption capacity at equilibrium in $\mathrm{g} / \mathrm{g}$.

\section{Determination of Gel Content}

Gel content of hydrogels is a measure of crosslinking. Higher gel content signifies higher percentage of crosslinking, but it does not ensure higher water absorbency. There should make a balance between gel content i.e. crosslinking to keep higher water absorbency. For the determination of gel content, a fixed amount of hydrogel sample, was dried to a constant weight and then immersed in $150 \mathrm{ml}$ of distilled water for $24 \mathrm{~h}$, with mild stirring to remove sol fractions. Then, the swelled samples were taken out of the distilled water and dried to a constant weight in an oven. The gel content was calculated [26] as follows:

$$
\text { Gel content }(\%)=\left(\mathrm{W}_{\mathrm{d}} / \mathrm{W}_{\mathrm{i}}\right) \times 100(2)
$$

where, Wd is the weight of dry gel after extraction in water and Wi is the initial weight of dry gel. 


\section{Dependency of pH on Swelling}

One of the current expected property of hydrogel is, the product would be $\mathrm{pH}$ responsive. To determine swelling behavior at various $\mathrm{pH}$, buffer solution, at a chosen $\mathrm{pH}$, was prepared and water absorbency of hydrogels was calculated at that pH using Eqn. 1.

Determination of Water Retention Capacity at Various

\section{Temperature}

Water retention capacity of hydrogel is as important as absorption capacity in context of application. To determine retention capacity, initially the water absorption capacity of synthesized hydrogels was tested in distilled water, using Equation 1 . Then the sample were taken at different temperatures $\left(5^{\circ} \mathrm{C}, 25^{\circ} \mathrm{C}\right.$ and $35^{\circ} \mathrm{C}$ ) and reweighed at that temperature at different time intervals. Obtained data were plotted graphically.

\section{FT-IR Analysis}

For identification of pure CMC, hydrogels with and without antimicrobial agents FTIR (Model: FTIR-8900, Shimadju, Japan) was conducted within the frequency range from 400 to $4000 \mathrm{~cm}^{-1}$ using $\mathrm{KBr}$ technique.

\section{Morphology of Hydrogels}

Surface morphology i.e. close and intense observation of the prepared hydrogels were performed by SEM analysis (JEOL, Model-JSM-7600F, and Japan). The micrographs were taken at a magnification of 3000 and 5000 times using (5-20 kV) accelerating voltage. The samples were coated with a thin layer of gold alloy by sputtering to improve the surface conductivity.

\section{Thermal Analysis of Sample}

Thermogravimetric analysis, TGA, can provide useful information about thermal behavior i.e. change of nature on applying heat, for a synthesized product. TGA measures a sample's weight change as it is heated or cooled in a furnace. It shows the degradation scenario of samples on application of heat. DTG refers to the mass loss rate with temperature and DTA/DSC curves determine the nature of the reaction, i.e. whether the reaction is exothermic or endothermic.

\section{Biodegradability Test (Soil Burial Method)}

Garden soil about $1200 \mathrm{~g}$ was taken in different pots. One gram of the sample wrapped with synthetic net was placed in the pot (covered with $\mathrm{Al}$ foil) such that the soil covered the polymer from all the sides. The weight of all the sample was taken at regular interval of 10 days. Percent weight loss was determined [27]:

$$
\text { Loss in weight, } \%=\frac{\text { Initial weight at the begining-Final weight after ten days }}{\text { Initial weight at the begining }} \times 100
$$

\section{Anti-microbial Activity Test}

The qualitative evaluation of antimicrobial activities of the prepared hydrogel was performed by versatile, easy and reliable agar well disk diffusion method against gram negative (E. coli) and gram positive (S. aureus) bacteria [28]. Quantitative analysis for antimicrobial agents was performed by percentage bacterial reduction [28].

\section{Results and Discussion}

As mentioned before that the hydrogel products were prepared by graft copolymerization of acrylamide and methyl methacrylate onto carboxymethyl cellulose in presence of $\mathrm{K}_{2} \mathrm{~S}_{2} \mathrm{O} 8$ as a free radical initiator and MBA as a crosslinking agent and two anti-microbial agents $\mathrm{ZnO}$ and $\mathrm{TiO}_{2}$. The suggested mechanism for hydrogel preparation is shown in Figure 1. According to the proposed mechanism $\mathrm{K}_{2} \mathrm{~S}_{2} \mathrm{O} 8$ produces sulfate anion radicals on heating and agitation, which reacts with hydroxyl groups of $\mathrm{CMC}$ to form more active macro radicals. The macro radicals attack the monomers (Am and MMA) to propagate a polymeric chain and there after become free radical donor to neighboring molecule to enlarge grafted chain. The polymeric chain simultaneously react with MBA to form crosslinked structure of hydrogel (Figure 1).

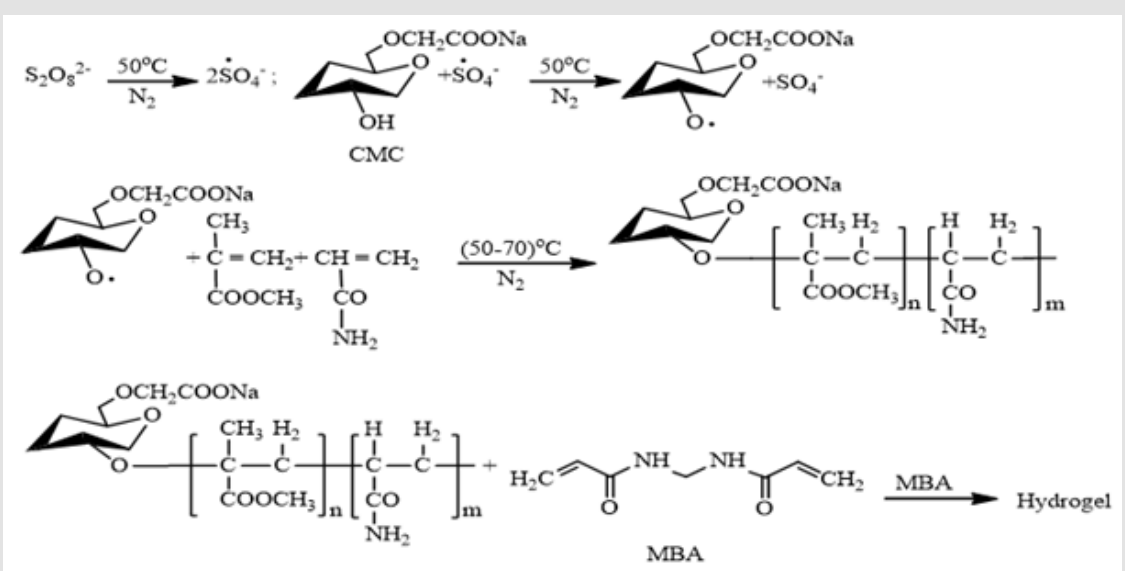

Figure 1: Reaction mechanism for the preparation of CMC-g-poly(Am-co-MMA) hydrogel (adapted with ref. 21). 


\section{Effect of Factors on Water Absorption}

Water absorption capacity is a very important criteria for hydrogel. For this purpose a definite amount of hydrogel sample is immersed in deionized water and made opportunity for swelling for $24 \mathrm{~h}$ and then water absorption capacity is measured according to Eqn. 1 (Figure 2). Figure 2a shows that when $\mathrm{TiO}_{2}$ as well as $\mathrm{ZnO}$ is increased, the degree of swelling of prepared hydrogels is decreased because both the agents stay in the hydrogel matrix and hydrogel surface and fills the pores of hydrogel. The swelling capacity of $\mathrm{ZnO}$ modified hydrogels is slightly lower than that of $\mathrm{TiO}_{2}$ modified. It is shown in Figure $2 \mathrm{~b}$ that swelling ratio i.e. water absorption capacity of both the antimicrobial agents $\left(\mathrm{TiO}_{2}\right.$ and
ZnO) containing hydrogels show better performance in alkaline medium than acidic medium. At neutral medium water absorption capacity is highest for the two samples due to presence of more number of hydrophilic groups in the medium. It is well-known that water uptake of the "ionic" hydrogel is affected greatly by the ionic strength of the solution [29]. In alkaline medium the swelling ratio of the hydrogel increased substantially because the amide group become more prone to hydrolysis and the hydrogen-bonding interactions from groups of $-\mathrm{COOH}$ (protonation of carboxylate ions obtained from methyl methacrylate) were broken, increasing the electrostatic repulsion between-COO-groups, and the polymer networks tended to swell more.
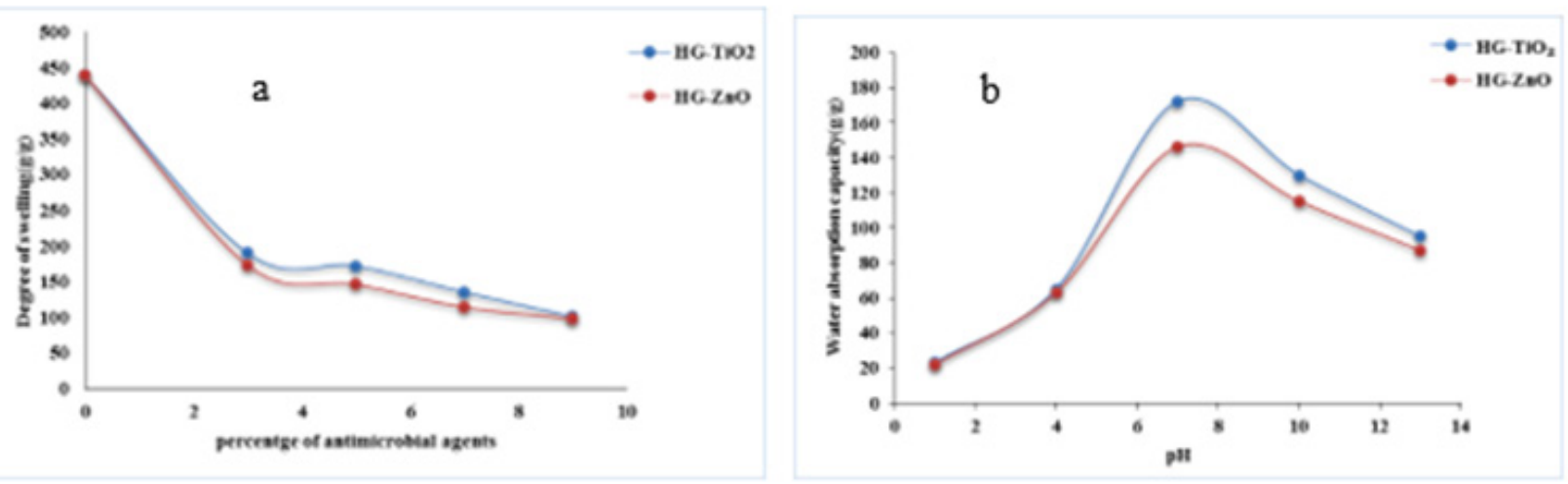

Figure 2: Determination of degree of swelling/ water absorption capacity of prepared hydrogels: (a) with different concentration of Titanium dioxide and Zinc oxide in aqueous medium and (b) effect of $\mathrm{pH}$.

The carboxylate group of methyl methacrylate ionizes and the mutual ionic repulsion between these groups caused the molecule to adopt a greatly expanded configuration, which opened up the polymer matrix leading to higher swelling of the matrix. In the case of higher $\mathrm{pH}$ (7-10), the dominant charges in the poly(Am-coMMA) are dissociated into carboxylate group -COO-, which results increase an osmotic pressure and makes the poly(Am-co-MMA) swell. Along with decreasing $\mathrm{pH}$, the amount of -COO- is gradually reduced inside the hydrogels, which leads to a decrease in osmotic pressure and makes the SR (swelling ratio) of the hydrogels smaller. Therefore the SR of poly(Am-co-MMA) gradually decreased. From Figure $2 \mathrm{~b}$ it is shown that the SR (water absorption capacity) was significantly increased with the rise of $\mathrm{pH}$ to the range of $\mathrm{pH}$ 7.0-10. This could be attributed due to an increase of the mobile ions -COOinside the hydrogel, electrostatic repulsion of the ions and rise in osmotic pressure inside the gel, which leads polymer in swelling state. When $\mathrm{pH}<7$, (in acidic condition) the dissociation of the carboxyl group being hindered resulted in a decrease of $-\mathrm{CO}_{2}$ in poly(Am-co-MMA) and less swelling was observed.

\section{Determination of Gel Content of Hydrogel}

Gel fraction influences the degree of crosslinking formed in the hydrogel [30]. If the degree of crosslinking is high then it produces a strong gel and it makes the structure rigid and reduces the ability to absorb water. Excessive crosslinking results in increasing the size of the crosslinked polymer with decreasing solubility. Table 1 shows that increasing both percentage of $\mathrm{TiO}_{2}$ and $\mathrm{ZnO}$ decreases gel fraction of hydrogels. As the agents remain in hydrogel matrix and decreases degree of crosslinking, so gel fraction becomes lower on increase of antimicrobial agents percentage. Figure 3a shows equilibrium water absorbency of hydrogels. It is seen from Figure 3a that hydrogel without antimicrobial agent has higher water absorption capacity than the antimicrobial samples and almost $65 \%$ of water had been absorbed by the hydrogel samples within 1 hour. The trend of water absorption remains almost same in case of antimicrobial hydrogels also, which makes the material suitable for personal health care products. Figure $3 \mathrm{~b}$ shows that water holding capacity of the three hydrogels are almost same but hydrogel without antimicrobial agent has higher than the other two. This less capacity of the former may be due to presence of the antimicrobial agents. It is clear from the previous discussion that the antimicrobial agents decreases crosslinking of hydrogels, which results less water absorption as well as low desorption rate. 

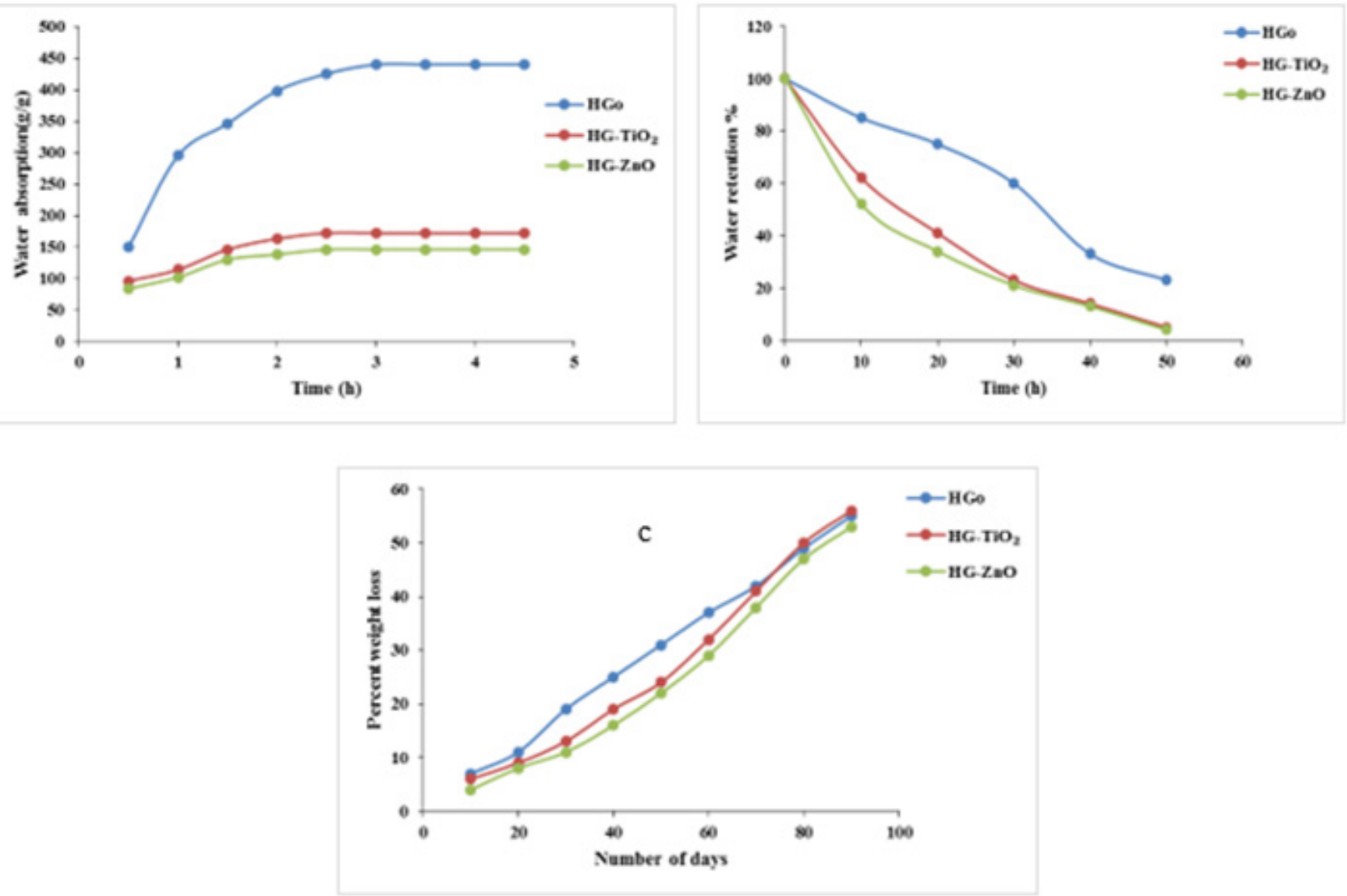

Figure 3: a) The effects of equilibrium time on water absorption, b) Water retention data and c) Degradation profile of hydrogel without antimicrobial agent, hydrogel with $5 \% \mathrm{TiO}_{2}$ and with $5 \% \mathrm{ZnO}$.

Table 1: Determination ofgel content of prepared hydrogel with differentconcentration of $\mathrm{TiO}_{2}$ and $\mathrm{ZnO}$.

\begin{tabular}{|c|c|c|c|}
\hline $\begin{array}{c}\text { Prepared hydrogel sample with } \\
\mathrm{TiO}_{2}\end{array}$ & $\begin{array}{c}\text { Gel fraction in hydrogel } \\
\text { samples(\%) }\end{array}$ & $\begin{array}{c}\text { Prepared hydrogel sample with } \\
\text { ZnO }\end{array}$ & $\begin{array}{c}\text { Gel fraction in hydrogel } \\
\text { samples(\%) }\end{array}$ \\
\hline Samplewith $0 \% \mathrm{TiO}_{2}$ & 87.50 & Samplewith 0\% ZnO & 87.50 \\
\hline Samplewith $3 \% \mathrm{TiO}_{2}$ & 82.60 & Samplewith 3\% ZnO & 75 \\
\hline Samplewith $5 \% \mathrm{TiO}_{2}$ & 77.77 & Samplewith 5\% ZnO & 70 \\
\hline Samplewith $7 \% \mathrm{TiO}_{2}$ & 67.85 & Samplewith 7\% ZnO & 65.21 \\
\hline Samplewith 9\% $\mathrm{TiO}_{2}$ & 62.50 & Samplewith 9\% $\mathrm{ZnO}$ & 58.33 \\
\hline
\end{tabular}

Again Figure 3c shows the biodegradable nature of the hydrogel products. The samples were examined by soil burial test for 90 days and about 55 60\% of weight was degraded after burial in soil during this period. $\mathrm{TiO}_{2}$ containing antimicrobial hydrogel shows a little bit higher degradable nature than $\mathrm{ZnO}$ containing hydrogel. This may be the reason that as $\mathrm{ZnO}$ occupies least pores of the polymer and increases degree of crosslinking, so less degradation is observed. Again when surface bonds are broken the degradation of antimicrobial hydrogels are relatively rapid [27].

\section{Anti-Microbial Activity Test}

Figure $4 \mathrm{a}$ and Figure $4 \mathrm{~b}$ show the antimicrobial activity test of hydrogels containing different amount of $\mathrm{ZnO}$ and $\mathrm{TiO}_{2}$ against gram negative (E. coli) and gram positive ( $S$. aureus) bacteria. It can be seen that both the agents are active against gram positive and gram negative bacteria and the capability to work against the microorganism increases on increasing antimicrobial agents. In both Figure $4 \mathrm{a} \&$ Figure $4 \mathrm{~b}$, it is clear that zone of inhibition, significance to antimicrobial action has been formed. It is also found 
that in both dishes, hydrogels without agents are not forming any clear zone around them. The results obtained from the above two figures are listed in Table 2 below. From Table 2 it can be seen that, on increasing concentration of antimicrobial agents $\mathrm{TiO}_{2}$ and $\mathrm{ZnO}$, against $S$. aureus and $E$. coli size of zone of inhibition of both become larger. Again, it is also concluded that both of the antimicrobial agents are more active against gram-negative bacteria (E. coli) than gram-positive. As antimicrobial agents containing hydrogels created larger zone of inhibition area in contact with gramnegative bacteria (E. coli), which signifies that the agents are more susceptible to gram negative bacteria than gram positive bacteria (S. aureus). On the other hand, between the two agents, $\mathrm{TiO}_{2}$ demonstrated more antimicrobial action than $\mathrm{ZnO}$, as well as being more reactive against gram-negative bacteria. From the obtained results shown in above Table $2, \mathrm{TiO}_{2}$ appears to be better microbial agent than $\mathrm{ZnO}$.
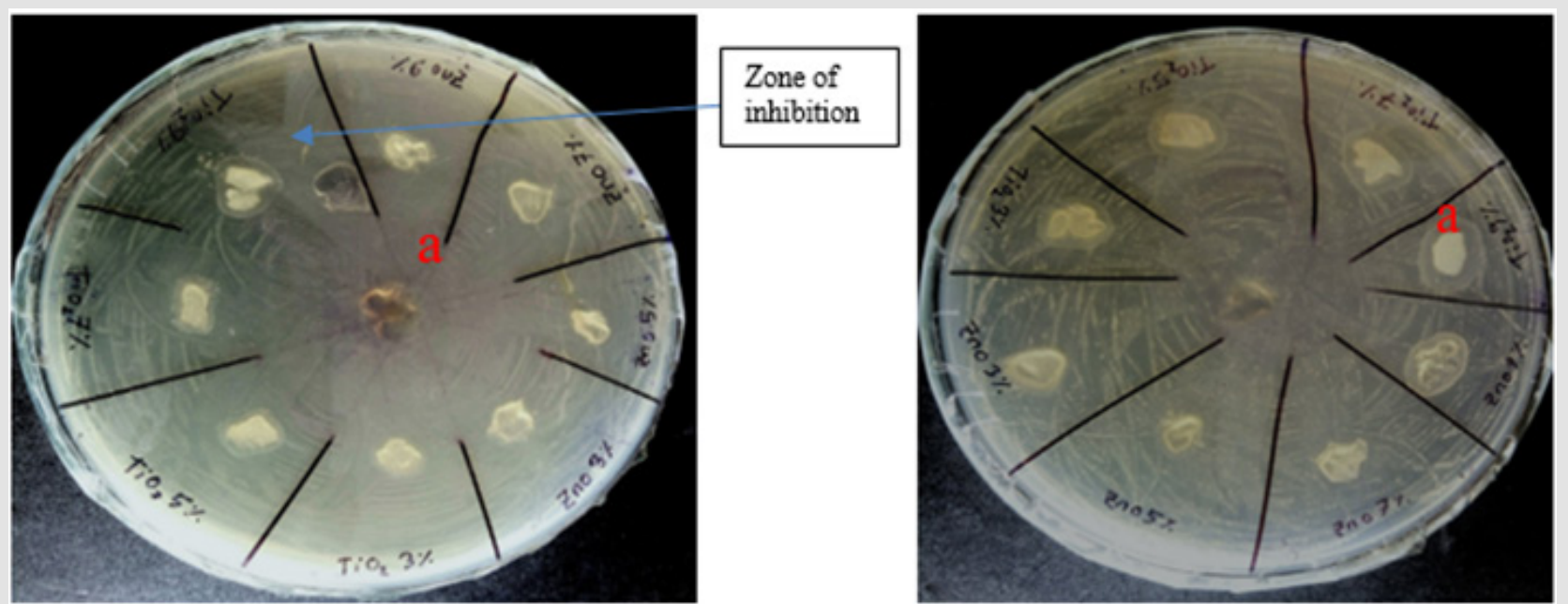

Figure 4: Anti-microbial activity test of prepared hydrogel samples by zone inhibition: (a) Against S. aureus additives free hydrogel sample (controlled) -a in both petredish; and with different concentration of $\mathrm{ZnO}$ and $\mathrm{TiO}_{2}$, and (b) Against E. coli.

Table 2: Determination of antimicrobial activity of prepared CMC-g-poly(Am-co-MMA) hydrogel by calculating Zone of inhibition with different concentration of $\mathrm{TiO}_{2}$ and $\mathrm{ZnO}$ against gram positive bacteria (S. aureus) and gram negative (E. coli).

\begin{tabular}{|c|c|c|c|c|}
\hline Name of microorganism & Sample with $\%$ of $\mathrm{TiO}_{2}$ & Zone of inhibition (Mm) & Sample with \% of ZnO & Zone of inhibition (Mm) \\
\hline \multirow{5}{*}{ S. aureus } & 0 & 0 & 0 & 0 \\
\hline & 3 & 1 & 3 & 0.5 \\
\hline & 5 & 2 & 5 & 1 \\
\hline & 7 & 3 & 7 & 2 \\
\hline & 9 & 4 & 9 & 4 \\
\hline \multirow{4}{*}{ E. coli } & 3 & 2 & 3 & 1.5 \\
\hline & 5 & 4 & 5 & 2 \\
\hline & 7 & 6 & 7 & 3 \\
\hline & 9 & 10 & 9 & 5 \\
\hline
\end{tabular}

Mechanism to work against microorganism to reproduction is different in case of numerous antimicrobial agents. Generally common strategy of antimicrobial is to penetrate into the cell membrane, to cause the leakage of cellular constituents and to damage DNA and RNA of bacteria [31]. The photo catalytic generation of hydrogen peroxide has been reported for the antimicrobial mechanism of $\mathrm{ZnO}$ [32]. Minimum Inhibition Concentration (MIC) describes the minimum concentration of the agent in which the multiplication of the bacteria is inhibited. For being different in structure, and bondage with hydrogels of different agents have variation in antimicrobial activity. In case of $\mathrm{ZnO}$ the MIC is $0.5 \%$ weight, on the basis of main component (i.e. $\mathrm{CMC}$ ) and in case of $\mathrm{TiO}_{2}$, it is $0.75 \%$. From the above Figure 5 it is found that no clear zone was formed around the hydrogel in case of both microorganisms. Same result was also found with $\mathrm{TiO}_{2}$ containing hydrogel. The antimicrobial action is believed to occur when the hydrogel's compounds are absorbed onto the bacterial cell's surface, increasing the permeability of the lipid cell membrane and causing death through the loss of essential cell materials. This effect is believed to be due to adsorption of $\mathrm{ZnO}$ and $\mathrm{TiO}_{2}$ in hydrogel onto the bacterial cell surface and membrane, with subsequent disruption of membrane integrity during swelling. 

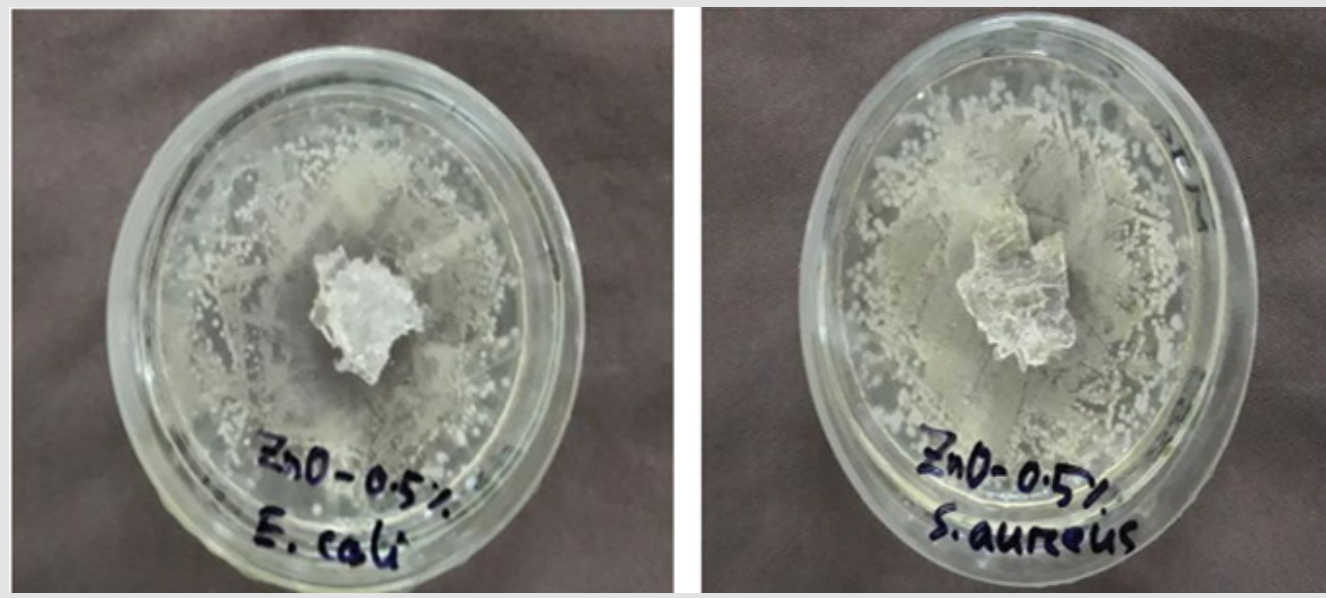

Figure 5: MIC (\% wt) determination of antimicrobial agents $\mathrm{ZnO}$ against gram negative bacteria (E. coli) and gram-positive bacteria (S. aureus).

Although the agent $\mathrm{TiO}_{2}$ showed better performance against microorganisms [E. coli and S. aureus] than $\mathrm{ZnO}$, but the MIC value is higher than $\mathrm{ZnO}$, this might be due to non-exposure of the agent and entrapment inside the hydrogel sample during swelling.

\section{Quantitative Evaluation of Antimicrobial Action}

Quantitative analysis of antimicrobial activity is based on inoculating test hydrogel samples with chosen test organisms at $8.42 \times 107$ (colony-forming units/mL) CFU/mL of E. coli and $5.26 \times 10^{7}$

Table 3: Bacterial Reduction (\%) of test hydrogel samples containing various percentage of $\mathrm{ZnO}_{\text {and }} \mathrm{TiO}_{2}$ against E. coli and S. aureus.

\begin{tabular}{|c|c|c|c|c|}
\hline Name of Microorganism & $\begin{array}{l}\text { Name of Hydrogel Sample } \\
\text { (HG) }\end{array}$ & Bacterial Reduction(\%) & $\begin{array}{c}\text { Name of Hydrogel Sample } \\
\text { (HG) }\end{array}$ & Bacterial Reduction(\%) \\
\hline \multirow{4}{*}{ E. coli } & $\mathrm{HG}-3 \% \mathrm{ZnO}$ & 28 & $\mathrm{HG}-3 \% \mathrm{TiO}_{2}$ & 45 \\
\hline & $\mathrm{HG}-5 \% \mathrm{ZnO}$ & 40 & $\mathrm{HG}-5 \% \mathrm{TiO}_{2}$ & 60 \\
\hline & $\mathrm{HG}-7 \% \mathrm{ZnO}$ & 55 & $\mathrm{HG}-7 \% \mathrm{TiO}_{2}$ & 73 \\
\hline & $\mathrm{HG}-9 \% \mathrm{ZnO}$ & 85.2 & $\mathrm{HG}-9 \% \mathrm{TiO}_{2}$ & 92.8 \\
\hline \multirow{4}{*}{ S. aureus } & $\mathrm{HG}-3 \% \mathrm{ZnO}$ & 42 & $\mathrm{HG}-3 \% \mathrm{TiO}_{2}$ & 52 \\
\hline & $\mathrm{HG}-5 \% \mathrm{ZnO}$ & 56 & $\mathrm{HG}-5 \% \mathrm{TiO}_{2}$ & 69 \\
\hline & $\mathrm{HG}-7 \% \mathrm{ZnO}$ & 80 & $\mathrm{HG}-7 \% \mathrm{TiO}_{2}$ & 75 \\
\hline & HG-9\%ZnO & 92.3 & $\mathrm{HG}-9 \% \mathrm{TiO}_{2}$ & 83 \\
\hline
\end{tabular}

\section{Instrumental Characterization}

Instrumental Characterization is very much essential for a product to ensure expected chemical reaction. If the synthesized sample was characterized by various instruments, obtained data would be more reliable as well as authentic. Figure 6 shows the FTIR spectra of CMC, prepared hydrogels (hydrogel without antimicrobial agent), hydrogel with $5 \% \mathrm{TiO}_{2}$ and with $5 \% \mathrm{ZnO}$. It can be seen that the spectra a (for CMC) differs from spectra $b$ (for
$\mathrm{CFU} / \mathrm{mL}$ of $S$. aureus usually in nutrient broth [28]. The obtained results are arranged in Table 3. Percentage bacterial reduction is a meaningful form of quantitative analysis for antimicrobial agents. From Table 3 it can be concluded that, on increasing the amount of antimicrobial agents in hydrogel samples, the hydrogels' capacity to fight against microorganisms also increases. This fact also supports the qualitative test (zone of inhibition) result of E. coli. The above result defers from previous result (Table 2) in case $S$. aureus and this may be due to exposure of the active ingredient in contact with the solution containing microorganisms. 
and at $800 \mathrm{~cm}^{-1}$ gives the evidence of presence of antimicrobial agents $\mathrm{ZnO}$ and $\mathrm{TiO}_{2}$ respectively.

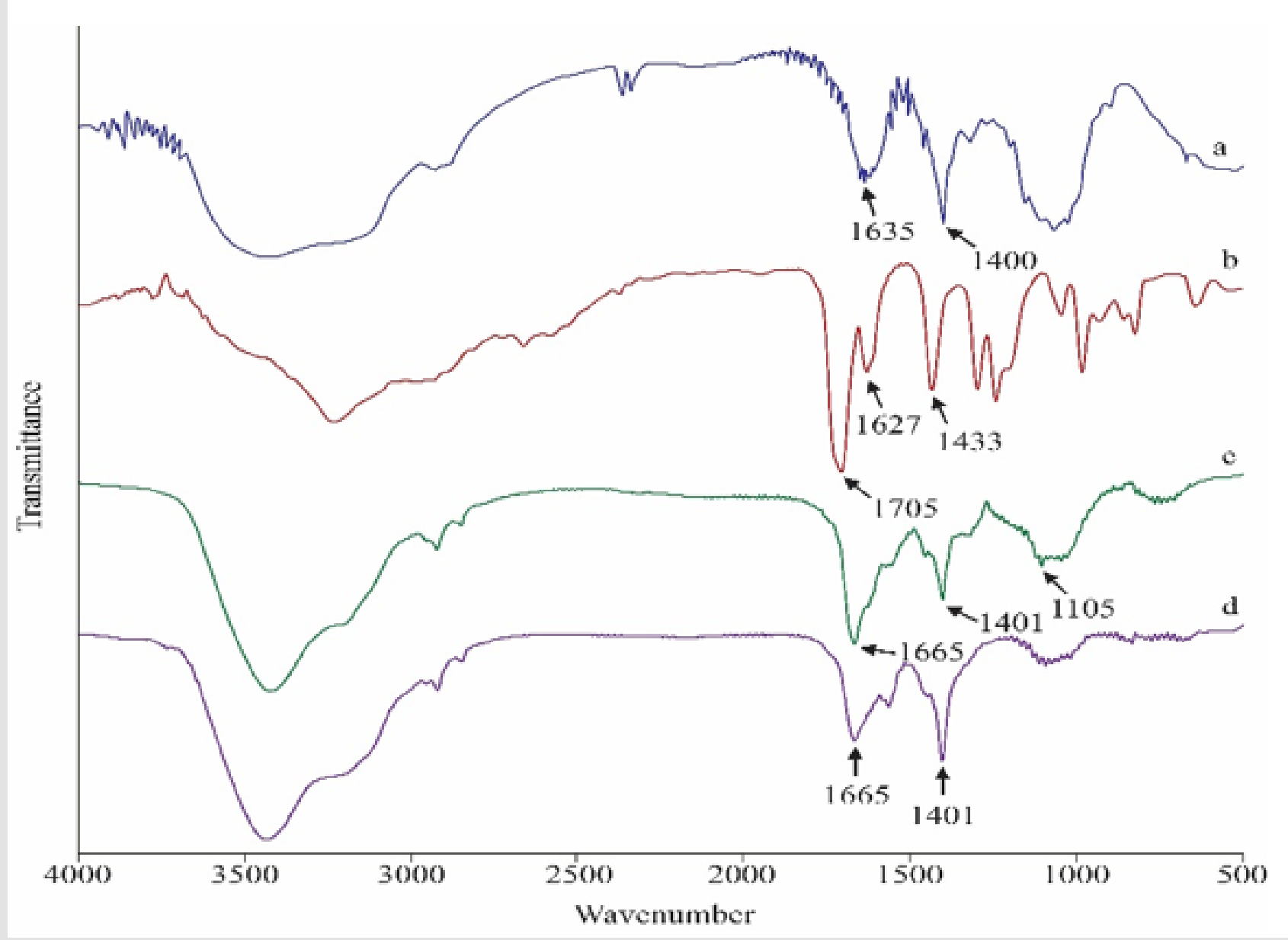

Figure 6: FTIR spectra of (a) CMC, (b) CMC-g-poly(Am-co-MMA) hydrogel (c) CMC-g-poly(Am-co-MMA)hydrogel with 5\% $\mathrm{ZnO}$ and (d) CMC-g-poly(Am-co-MMA) hydrogel with $5 \% \mathrm{TiO}_{2}$.

SEM images of CMC, CMC-g-poly(Am-co-MMA) hydrogel and two antimicrobial agents containing hydrogels are shown in Figure 7 at various magnification. From the photographs it can be seen that, as CMC is a cellulose derivative it is tubular and fibrous in shape. Conversion of CMC to hydrogel the shape has been changed, which is a combination of amorphous and crystalline zones (Figure $7 \mathrm{~b}$ ). Due to incorporation of $\mathrm{ZnO}$ and $\mathrm{TiO}_{2}$ in the hydrogel samples only a small change in crystalline structure rather than amorphous area has been taken place, this may be due to deposition of the two compounds inside the crystalline zone. It is also observed that agglomeration on crystal structure is higher in case of $\mathrm{TiO}_{2}$ than $\mathrm{ZnO}$. The deposition of antimicrobial agents in both cases made samples non-porous, which results less water absorption. Thermal behavior of any product bears extra importance in context of application. Thermogravimetric (TG) analysis of hydrogels without and with antimicrobial agents are shown in Figure 8. Generally cellulose and cellulose derivatives show three degradation areas which is also observed in case of CMC. Compared to CMC, the degradation curves of rest of the hydrogels are not as sharp as in CMC. The first stage decomposition of the four compounds ranged from 25 to 240,325 , 310 and $110{ }^{\circ} \mathrm{C}$ respectively. In the first stage generally absorbed and bound water are removed and in case of higher temperature degradation of cellulose may occur [33]. All the four samples have similar degradation profile and the degradation process contains three stages, in all the cases. 


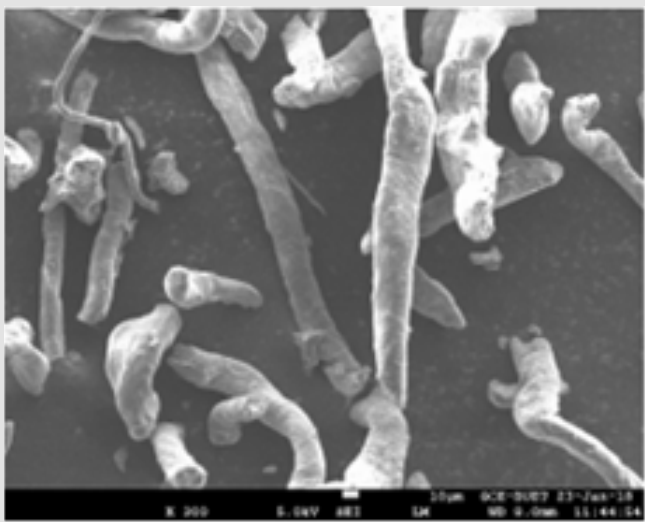

a

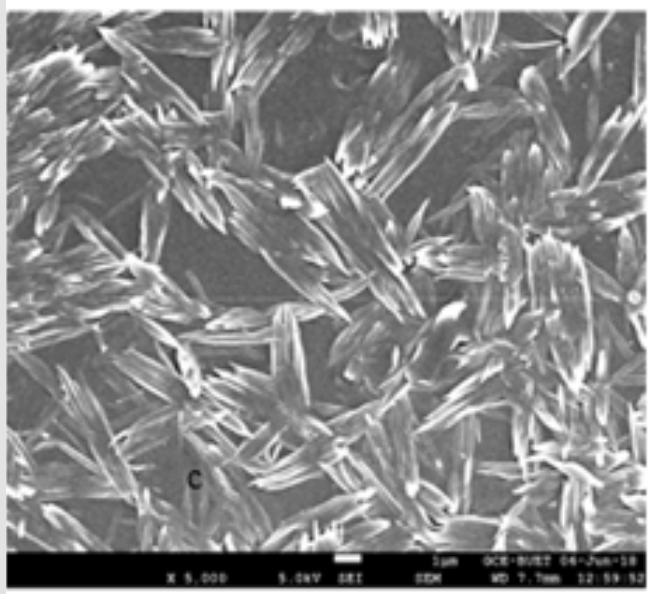

c

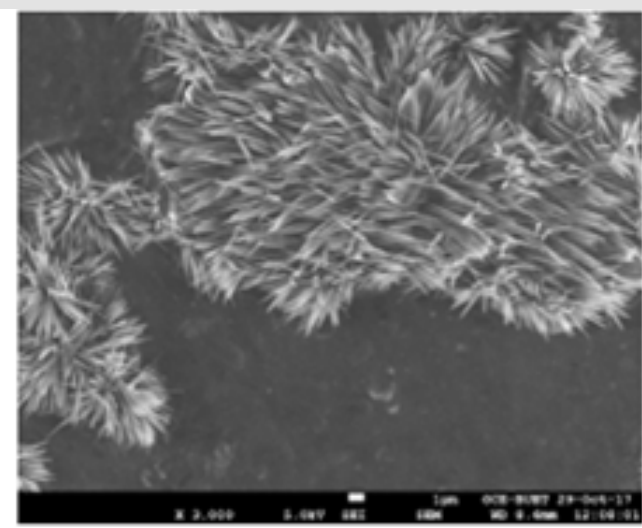

b

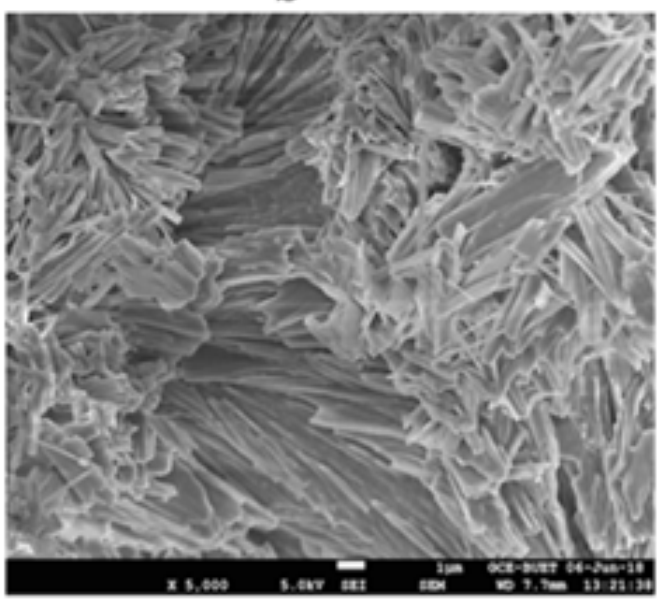

d

Figure 7: SEM images of (a) CMC; (b) [CMC-g-poly(Am-co-MMA)] hydrogel without anti- microbial agent; (c) CMC-gpoly(Am-co-MMA) hydrogel with $5 \% \mathrm{ZnO}\left(1 \mu \mathrm{m}\right.$ size bar) and (d) CMC-g- poly(Am-co-MMA) hydrogel with $5 \% \mathrm{TiO}_{2}$.

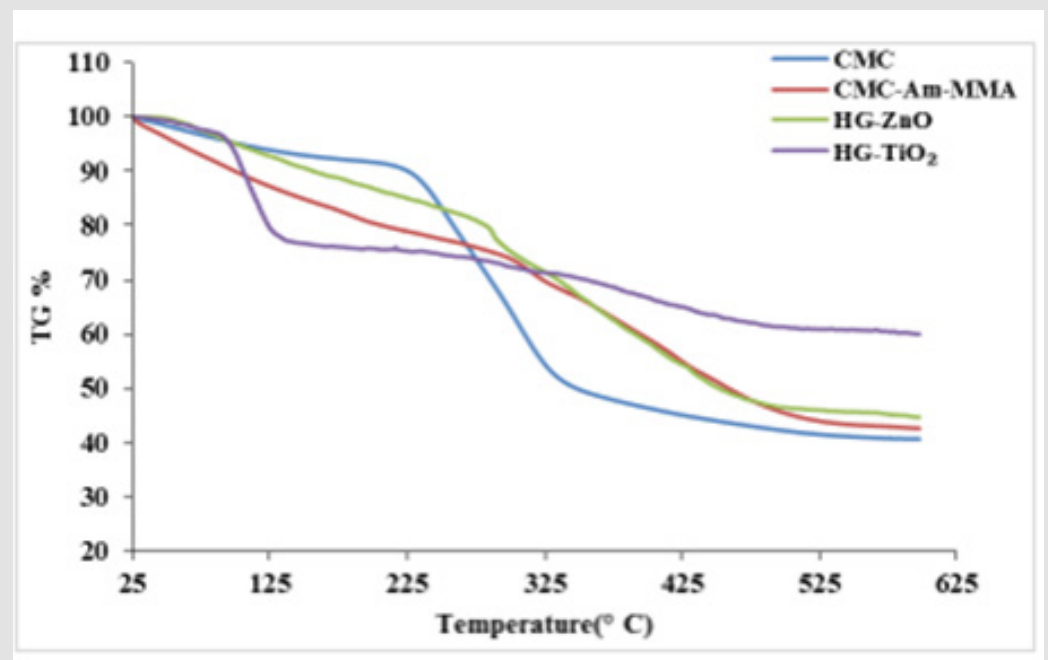

Figure 8: TG curve of CMC; [CMC-g-poly (Am-co-MMA)] hydrogel without anti- microbial agent; CMC-g-poly (Am-co-

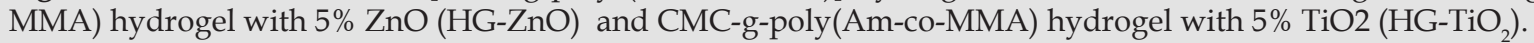


These observations confirm graft copolymerization have been taken place. Except hydrogel with $\mathrm{TiO} 2$ the other two samples [CMC-g-poly(Am-co-MMA) hydrogel without antimicrobial agent and same hydrogel with $5 \%$ zinc oxide $(\mathrm{ZnO})]$ had lower loss (Tiinitial decomposition) than CMC, again all the hydrogels have higher amount of char yield than CMC, which indicates that conversion of CMC to hydrogels with or without antimicrobial agents increased the thermal stability of CMC.

\section{Conclusions}

Hydrogels were synthesized by graft copolymerization of acrylamide and methyl methacrylate with CMC in presence of antimicrobial agents $\mathrm{TiO}_{2}$ and $\mathrm{ZnO}$. The three hydrogels (without antimicrobial agent, hydrogel with $5 \% \mathrm{TiO}_{2}$ and with $5 \% \mathrm{ZnO}$ ) show maximum water absorbency of $440,172,146 \mathrm{~g} / \mathrm{g}$ in deionized wat er respectively. The antimicrobial hydrogel samples are active against both gram positive and gram negative microorganisms. The determined MIC (minimum inhibition concentration) values of the antimicrobial agents are $0.5 \%$ for $\mathrm{ZnO}$ and $0.75 \%$ for $\mathrm{TiO}_{2}$ on the basis of base material (CMC) weight. So, it can be used in personal health care product, which would bring updated risk free physical conceptual change in this sector, at the same time further research is recommended for ultimate success in application of the product.

\section{References}

1. Buchholz FL, Graham AT (1998) Modern Superabsorbent Polymer Technology. Wiley-VCH New York, USA Ch 1-7.

2. Richter A, Howitz S, Kuckling D, Arndt KF (2004) Influence of volume phase transition phenomena on the behavior of hydrogel-based valves. Sensors and Actuators B 99(2-3): 451-458.

3. Haque MO, Mondal MIH (2016) Synthesis and Characterization of Cellulose- based Eco-Friendly Hydrogels. Journal of Science and Engineering 44: 45-53.

4. Karadag E, Uzum OB, Saraydin D, Guven O (2005) Dynamic swelling behaviour of radiation induced polyelectrolyte poly (AAM-co-CA) hydrogels in urea solution. International of Pharmaceutices 301(1-2): 102-111.

5. Thomas V, Yallapu MM, Sreedhar B, Bajpai SK (2007) A versatile strategy to fabricate hydrogel-silver nanocomposites and investigation of their antimicrobial activity. Journal of Colloid Interface Science 315(1): 389395.

6. Sadeghi M, Hosseinzadeh H (2008) Synthesis of Starch-Poly (Sodium Acrylate-co- Acrylamide) Superabsorbent Hydrogel with Salt and pH-Responsiveness Properties as a Drug Delivery System. Journal of Bioactive and Compatible Polymers 23(4): 381-404.

7. Maithili K, Ram M (2003) Disposable diapers: A hygienic alternative. Indian Journal of Pediatrics 70(11): 879-881.

8. Song FX, Wei JF, He TS (2009) A method to repair concrete leakage through cracks by synthesisizing super-absorbent resin in situ. Concrete and Building Materials 23(1): 386-391.

9. Bakass M, Mokhlisse A, Lallemant M (2002) Absorption and desorption of liquid water by a superabsorbent polymer: effect of polymer in the drying of the soil and the quality of certain plants. Journal of Applied Poymer Science 83(2): 234-243.

10. Pourjavadi SH, Barzegar, Zeidabadi F (2007) Synthesis and properties of biodegradable hydrogels of K-carrageenam grafted acrylic acid-co- 2-acryl amido-2-methyl propane sulfonic acid as canditaes for drug delivery systems. Reactive Functional Polymer 67(7): 644-654.

11. Kashyap N, Kumar N, Kumar M (2005) Hydrogels for Pharmaceutical and Biomedical Applications. Critical Review of Therapeutic Drug Carrier Systems 22(2): 107-149.

12. Balakrishnan B, Mohanty M, Umashankar PR, Jayakrishnan A (2005) Evaluation of an in situ forming hydrogel wound dressing based on oxidized alginate and gelatin. Biomaterials 26(32): 6335-6342.

13. Drury JL, Mooney DJ (2003) Hydrogels for tissue engineering: Scaffold design variables and applications. Biomaterials 24(24): 4337-4351.

14. Seliktar D (2005) Extracellular stimulation in tissue engineering. Annals New York Academy of Sciences 1047 (1): 386-394.

15. Jen AC, Wake MM, Mikos AG (1996) Hydrogels for cell immobilization. Biotechnology and Bioengineering 50(4): 357-364.

16. Shang J, Shao Z, Chen X (2008) Electrical behavior of a natural polyelectrolyte hydrogel: Chitosan/ carboxymethylcellulose hydrogel. Biomacromolecules 9(4): 1208-1213.

17. Eichhorn SJ, Dufresne A, Aranguren M, Marcovich NE, Capadona JR, et al. (2010) Current international research into cellulose nanofibers and nanocomposites. Journal of Material Sciences 45(1): 1-33.

18. Kamitz JrO, Gurgel LVA, de Melo JCP, Botaro VR, Melo TMS, et al. (2007) Adsorption of heavy ions metals from aqueous single metal solution by chemically modified sugarcane bagasse. Bioresource Technology 98(6): 1291- 1297.

19. Rodrigues RF, Trevezoli RL, Santos LRG, Leao VA, Botaro VR, et al. (2006) Heavy metals sorption on treated wood saw dust. Eng. Samit. Ambient 11(1): 21-26.

20. Wang SY, Wang LP, Kong WQ Ren JL, Liu CF, et al. (2013) Preparation, characterization of carboxylated bamboo fibers and their adsorption for lead (II) ions in aqueous solution. Cellulose 20(4): 2091-2100.

21. Liang XT, Huang ZQ Zhang YJ, Liu Z (2013) Synthesis and properties of novel superabsorbent hydrogels $n$ with mechanically activated sugarcane bagasse and acrylic acid. Polymer Bulletin 70(6): 1781-1794.

22. Kim MN, Lee AR, Yoon JS, Chin IJ (2000) Biodegradation of poly(3hydroxybutyrate), Sky-Green and Mater-Bi by fungi isolated from soils. European Polymer Journal 36(8): 1677-1685.

23. Haque MO, Mondal MIH (2019) Cellulose-Based Hydrogel for Personal Hygiene Applications (Chapter 45), In: Cellulose-Based Superabsorbent Hydrogels (Vol. II), Md. Ibrahim H. Mondal (Editor), Springer Nature, Switzerland pp. 1339-1359. ISBN: 978-3-319-77829-7 (Hardcover), ISBN: 978-3-319-77830-3.

24. Marc G, Mele G, Palmisano L, Pulit P, Sannino A, et al. (2006) Environmentally sustainable production of cellulose-based superabsorbent hydrogels. Green Chemistry 8: 439-444.

25. Bao Y, Ma J, Li N (2011) Synthesis and swelling behaviors of sodium carboxymethyl cellulose-g-poly (AA-co-AM-co-AMPS)/MMT superabsorbent hydrogel. Carbohydrate. Polymer 84(1): 76-82.

26. Krusic MK, Milosavlievic N, Debelikovic A, Uzum OB, Karadag E, et al. (2012) Removal of $\mathrm{Pb}^{2+}$ ions from water by poly (acryl amide-co-sodium methacrylate) hydrogels. Water air Soil Pollutants 223(7): 4355-4368.

27. Kim MN, Lee AR, Yoon JS, Chin IJ (2000) Biodegradation of poly(3hydroxybutyrate), Sky-Green and Mater-Bi by fungi isolated from soils. European Polymer Journal 36(8): 1677-1685.

28. Rajendran R, Balakumar C, Ahammed HAM, Jayakumar S, Vaideki K, et al. (2010) Use of zinc oxide nano particles for production of antimicrobial textiles. International Journal of Engineering, Science and Technology 2(1): 202-208.

29. Pourjavadi A, Salimi H (2008) New protein-based hydrogel with superabsorbing properties: effect of monomer ratio on swelling 
behavior and kinetics. Industrial \& Engineering Chemistry Research 47(23): 9206-9213.

30. Radoslaw AW, Hiroshi M, Fumio Y, Tamikazu K (2001) Hydrogel of Biodegradable Cellulose Derivatives. II. Effect of Some Factors on Radiation-Induced Crosslinking of CMC. Journal of Applied Polymer Science 81(12): 3030-3037.

31. Sudarshan NR, Hoover DG, Knorr D (2009) Antibacterial action of chitosan. Journal of food Biochemistry 6: 257-272.

\section{ISSN: 2574-1241}

DOI: $10.26717 /$ BJSTR.2020.30.005000

Md. Ibrahim H. Mondal. Biomed J Sci \& Tech Res

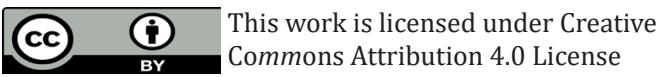

Submission Link: https://biomedres.us/submit-manuscript.php
32. Sawai J (2003) Quantitative evaluation of antibacterial activities of metallic oxide powders $(\mathrm{ZnO}, \mathrm{MgO}$ and $\mathrm{CaO})$ by conductimetric assay. Journal of Microbiological Methods 54(2): 177-182.

33. Zheng T, Fan L, Dong X (2007) Study on solid phase grafting copolymerization of cellulose and acrylic acid under ultrasonic waves. Journal of He Fei University of Technology 30(10): 1323-1326.

\begin{tabular}{ll} 
BIOMEDICAL & Assets of Publishing with us \\
RESEARCHES & - Global archiving of articles \\
\hline ISSN: $2574-1241$ & Immediate, unrestricted online access \\
& - Rigorous Peer Review Process \\
&
\end{tabular}

